\title{
Endoscopic transnasal management of sinonasal malignancies - our initial experience
}

Tomasz Gotlib, Ewa Osuch-Wójcikiewicz, Marta Held-Ziółkowska, Magdalena Kużmińska, Kazimierz Niemczyk

Department of Otolaryngology, Medical University of Warsaw, Poland

Videosurgery Miniinv 2014; 9 (2): 131-137

DOI: $10.5114 /$ wiitm.2014.41619

\begin{abstract}
Introduction: Malignant tumors of the paranasal sinuses are traditionally managed through external approaches. Advances in endoscopic transnasal surgery have allowed for the endoscopic treatment of some of these tumors.

Aim: To present the results of treatment of a series of patients with paranasal sinus malignancies treated with an endoscopic approach at a single institution.

Material and methods: The data on tumor type, operative technique, perioperative complications and postoperative course were analyzed.

Results: Eleven patients meeting the inclusion criteria were identified. The histopathology was as follows: malignant melanoma in 3 patients, squamous cell carcinoma in 2, adenocarcinoma in 2, poorly differentiated carcinoma in 1, hemangiopericytoma in 1, adenoid cystic carcinoma in 1 and fibrosarcoma in 1. There were no severe perioperative complications with the exception of 1 case of cerebrospinal fluid leak, which was successfully closed. The mean observation period was 13.5 months. One of the patients died of disease, another was lost to follow-up, and one was reoperated on due to recurrence. The remaining 8 patients are alive with no signs of recurrence.

Conclusions: Our initial experience seems to confirm results obtained by other authors indicating that in selected cases endoscopic surgery of sinonasal malignancies is similarly effective as external approach surgery.
\end{abstract}

Key words: sinonasal malignancy, tumor, paranasal sinuses, endoscopic.

\section{Introduction}

Malignant tumors of the paranasal sinuses and nasal cavity are rare, and account for $3 \%$ of all head and neck malignancies [1-3]. Most commonly they are diagnosed at an advanced stage due to non-specific symptoms at the initial phase of growth. Differences in histopathological type, site of origin, growth pattern, involvement of neighboring structures and presence of metastases influence the prognosis, which has been regarded as generally poor [4, 5]. Surgical resection is the most effective treatment modality in the majority of cases. Traditionally these tumors are removed through the external transfacial approaches. Tumors involving the skull base have been treated with a combined transfacial approach and craniofacial resection since the introduction of the latter procedure in the 1960s [6].

Endoscopic surgery was first introduced for the treatment of benign tumors of paranasal sinuses. Currently this approach is considered as a validated method of treatment of inverting papilloma or juvenile angiofibroma [3, 7-10]. Growing experience with endoscopic technique together with advances in visualization, the introduction of image guidance and development of surgical tools has led to a gradual shift towards the treatment of malignancies [3]. There has been a growing number of studies showing favorable 
outcomes of resection of sinonasal malignancies involving the skull base in the last decade [11-13].

\section{Aim}

The aim of this study was to present the results of treatment of a series of patients with paranasal sinus malignancies treated with an endoscopic approach.

\section{Material and methods}

We retrospectively reviewed the results of the treatment of patients with paranasal sinus malignancies treated with an endoscopic approach at a single institution between January 2010 and February 2013. The data on tumor type, operative technique, perioperative complications and postoperative course were analyzed.

\section{Operative technique}

The procedures were performed under general anesthesia. After decongesting the nasal mucosa with adrenaline-soaked cotton pledgets, the nasal cavity was inspected with a $30^{\circ}$ endoscope. Healthy tissues surrounding the tumor were removed (ethmoidectomy, septectomy) to gain access and assess its mobility and possible site of attachment. If necessary the tumor was debulked with a shaver (Unidrive motor system, Drill-Cut X handpiece, Karl Storz, Germany). After identification of the attachment of the tumor its site was removed with a margin and the underlying bone was removed with an irrigated curved burr $\left(5.0 \mathrm{~mm} 15^{\circ}\right.$ burr, or $\left.3.6 \mathrm{~mm} 70^{\circ}\right)$ and/or Kerrison punches. In tumors with wide attachment, dissection in the periosteal plane was performed. Further extension of the procedure depended on specific pathology, tumor advancement and individual anatomic variations.

Patients used saline nasal douches for 6 weeks after the operation, starting the day after surgery, or the day after the removal of nasal packing. Follow-up visits with debridement of crusts under endoscopic control were carried out every 7-14 days for at least 1 month, and then at least once in 3 months. Follow-up imaging was performed with computed tomography or magnetic resonance.

\section{Results}

Eleven patients who underwent endoscopic tumor removal were identified. The histopathology was as follows: malignant melanoma in 3 patients, squamous cell carcinoma in 2, adenocarcinoma in 2, poorly differentiated carcinoma in 1 , hemangiopericytoma in 1, adenoid cystic carcinoma in 1, and low grade fibrosarcoma in 1 . An overview of patients is presented in Table I.

Preoperative biopsy was performed in 8 patients. In 2 a frozen section was obtained intraoperatively. The greatest dimension of the tumor varied between 2 and $6 \mathrm{~cm}$.

Preoperative imaging (magnetic resonance imaging - MRI, computed tomography - CT) did not clearly indicate the site of origin in any subjects, but after debulking of the tumor it could clearly be seen in 6 cases.

Four patients underwent subsequent radiotherapy. In 1 patient selective neck dissection was performed due to metastasis of malignant melanoma (Table I, patient 9). The mean observation period was 13.5 months (range: 4-20 months).

In 2 cases the lesion extended to the skull base. In one of them the tumor (patient 2) was adherent to the fovea ethmoidalis (Photo 1). After resection of the middle turbinate and upper nasal septum and performing the Draf III procedure, the bone of fovea ethmoidalis was removed with a diamond burr. The exposed dura was covered with a mucoperiosteal flap harvested from the contralateral middle turbinate. In the second case the tumor filled the upper part of the right sphenoid sinus and penetrated intracranially anteriorly to the optic chiasm. The right optic nerve and internal carotid artery were displaced by the tumor. Imaging (MRI, CT) did not show if the dura was compressed or infiltrated. The initial biopsy was not diagnostic. During the second procedure, after bilateral sphenoethmoidectomy and removal of the posterior bony nasal septum, the entire intrasphenoid and a fragment of the intracranial lesion were removed. The tumor was infiltrating the dura. Part of the lesion adherent to the optic nerve and carotid artery was left. The dural defect was reconstructed with vomer bone and abdominal fat. The postoperative course was uneventful. Histopathology revealed hemangiopericytoma. After a 1-year observation period control the MRI follow-up showed a considerable increase in size of the remnant. The patient was reoperated on transnasally. The skull base defect was reconstructed with abdominal fat and fascia lata. The patient was reoperated on due to cerebrospinal fluid (CSF) leak and the defect was successfully closed with the same technique. 
Table I. Overview of the patients

\begin{tabular}{|c|c|c|c|c|c|c|c|c|}
\hline $\begin{array}{l}\text { Patient } \\
\text { no. }\end{array}$ & Gender & $\begin{array}{c}\text { Age } \\
\text { [years] }\end{array}$ & Histopathology & $\begin{array}{l}\text { Dimension } \\
{[\mathrm{cm}]}\end{array}$ & Pedicle & $\begin{array}{l}\text { Skull } \\
\text { base }\end{array}$ & $\begin{array}{c}\text { Observation } \\
\text { [months] }\end{array}$ & Status \\
\hline 1 & $M$ & 85 & Adenocarcinoma & 2.5 & 1 & & 8 & $d d$ \\
\hline 2 & $\mathrm{~F}$ & 56 & Melanoma & 2.7 & 1 & Bone & 20 & afd \\
\hline 3 & $\mathrm{~F}$ & 82 & Melanoma & 2 & & & 19 & afd \\
\hline 4 & $M$ & 79 & Ca adenoid cysticum & 6 & & & 18 & afd \\
\hline 5 & $M$ & 28 & Hemangiopericytoma & 2.8 & & Dura & $17 / 1^{*}$ & afd \\
\hline 6 & $M$ & 39 & SCC & 2 & 1 & & 15 & afd \\
\hline 7 & $M$ & 68 & Poorly differ. ca & 2.7 & & & 14 & afd \\
\hline 8 & $\mathrm{~F}$ & 77 & SCC & 5 & 1 & & 14 & afd \\
\hline 9 & $\mathrm{~F}$ & 65 & Melanoma & 2.9 & & & 12 & lost \\
\hline 10 & $\mathrm{~F}$ & 64 & Fibrosarcoma & 3.1 & 1 & & 7 & afd \\
\hline 11 & $\mathrm{~F}$ & 75 & Adenocarcinoma & 4.8 & 1 & & 4 & afd \\
\hline Mean & & 65 & & 3.3 & & & 13.5 & \\
\hline
\end{tabular}

Dimension - the greatest dimension of the tumor, SCC - squamous cell carcinoma, afd - alive, free of disease, dd - died of disease, Lost - lost in follow-up, Skull base: skull base involvement, *the patient was observed for a total of 17 months after the first procedure, and 1 month after reoperation

There were no severe perioperative complications in the remaining patients.

\section{Discussion}

The main argument against endoscopic surgery of sinonasal and skull-base malignancies is the use of piecemeal resection rather than en bloc resection, which is easier to achieve with open approaches. Proponents of endoscopic surgery underline its minimal invasiveness and low morbidity [14]. Several studies have suggested that in selected cases endoscopic approaches are equally as efficient as open ones [11, 12].

A major advance in endoscopic sinonasal malignancy treatment was the introduction of the pedicled nasoseptal flap [15]. The use of this technique enables the efficient reconstruction of huge skull base defects. Indications for endoscopic surgery have been expanding with the development of instrumentation and reconstructive techniques. Most experience in this field comes from a few specialized expertise centers [14].

Despite large groups of patients available for follow-up, due to their diversity caused by differences in histopathology, stage of the disease, different types of adjuvant therapy, and lack of long-term follow-up, there are still controversies and open issues concerning this type of treatment $[3,14]$.
Our experience limited to 11 patients and short follow-up allows us only to focus on technical aspects of the procedures and discuss the cases of fibrosarcoma and hemangiopericytoma of clinically aggressive behavior, as rare entities.

The recognition of the infiltration pattern is important for resection planning. Pedicled tumors are much easier to remove compared to widely attached, deeply infiltrating lesions. In 1 of our patients (patient no. 8) a huge tumor filling the left nasal cavity and the entire nasopharynx was finally found attached to the upper-posterior part of the nasal septum with a narrow pedicle (Photo 2). No other sites of infiltration were found. The tumor was cut from the site of origin and removed transorally. The posterior septum and anterior wall of both sphenoid sinuses were removed.

Despite identification of the pedicle in 6 cases we failed to perform en bloc resection in these patients.

Preoperatively we were not able to detect the exact site of origin in the patients from our group; however, based on evaluation of CT and MRI using multiplanar reconstructions (MPR), together with careful endoscopic examination in some cases, it was possible to find the sites where the tumor adhered to the neighboring structures without infiltration. In contrast to pedicled tumors, broadly at- 

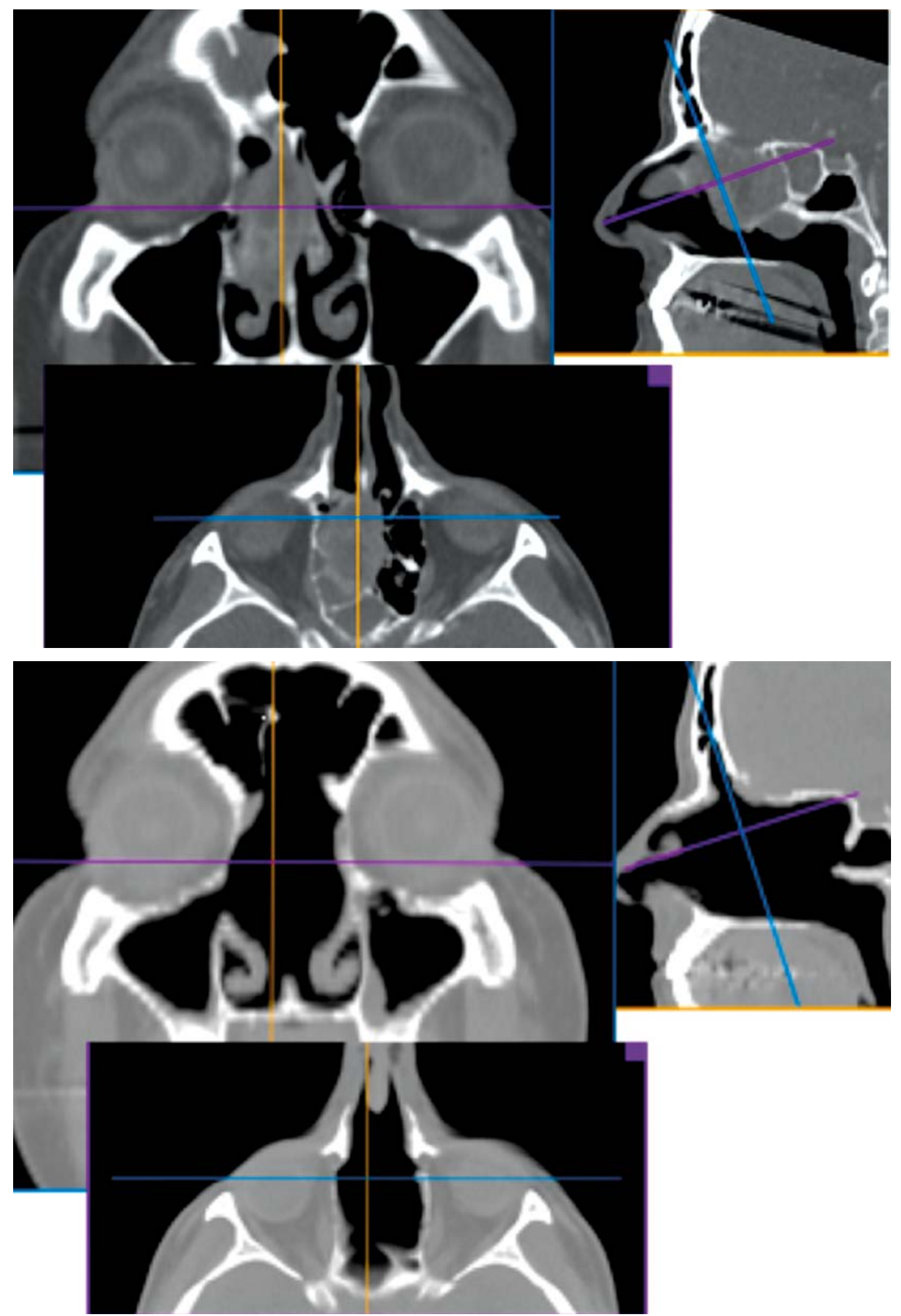

Photo 1. Computed tomography of the patient with malignant melanoma (patient 2) before (top) and after (below) the surgery 

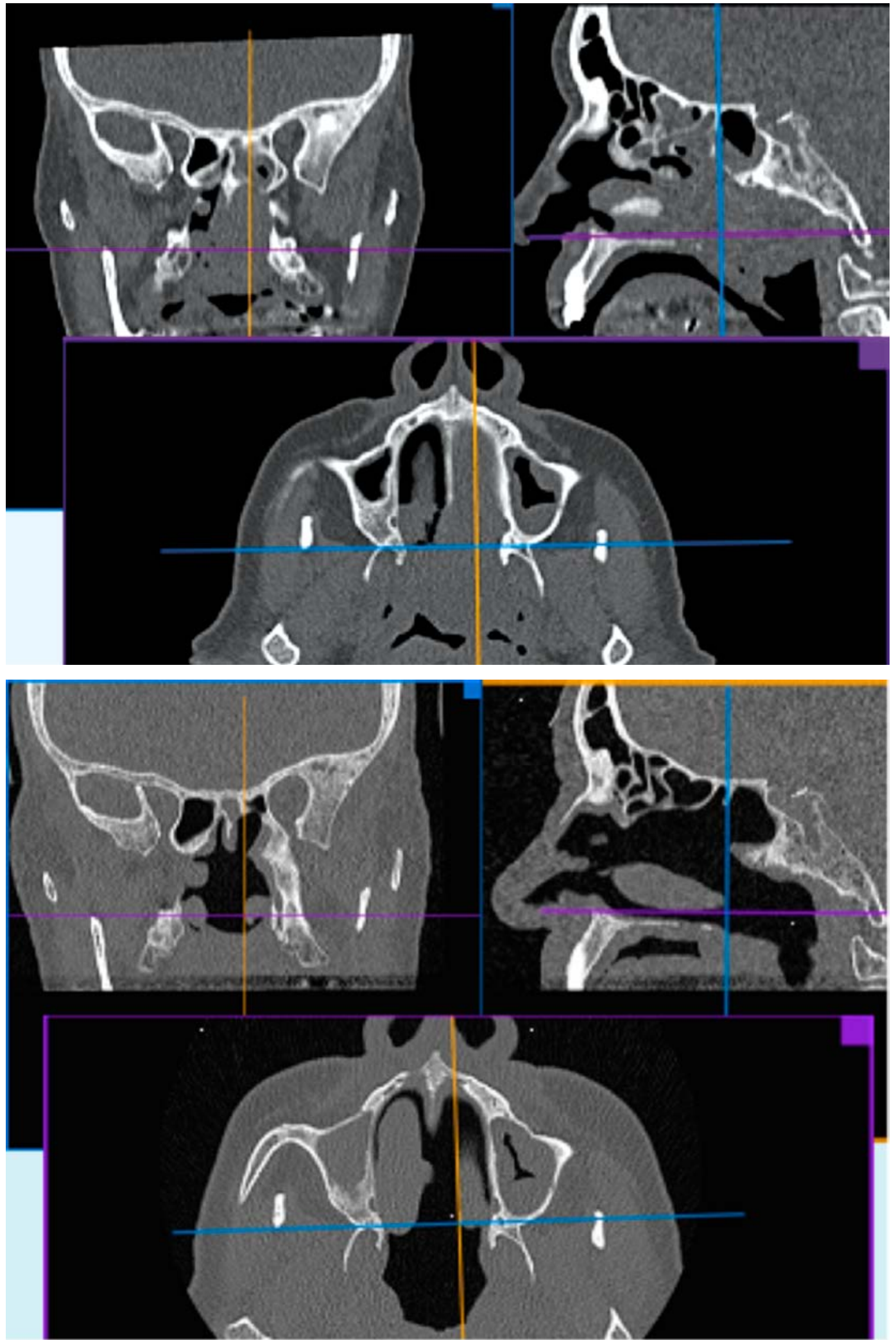

Photo 2. Computed tomography of the patient with SCC (patient 8) before (top) and after (below) the surgery 
tached lesions with an infiltrative pattern of growth are more technically challenging and require removal of tissue on a larger area without clear landmarks. In these cases it is more difficult to establish surgical margins, especially in vascularized lesions.

Hemangiopericytoma (HPC) is an uncommon, slowgrowing mesenchymal neoplasm regarded as a lowgrade sarcoma. Sinonasal hemangiopericytomas are extremely rare. There are only a few studies reporting long-term results of surgical treatment of sinonasal hemangiopericytoma from a single institution in the literature. All of them present a limited number of patients [16, 17]. Most of the authors consider these tumors clinically and biologically as benign lesions. Local recurrences were reported up to 13 years after surgical resection [16]. Metastasizing and locally aggressive HPC of head and neck was described in the literature [18]; however, in a study summarizing results of treatment of 104 sinonasal hemangiopericytomas from different institutions from a 25-year period, there was no single case of a metastasizing tumor [19]. We included a patient with HPC in our group due to its location and locally aggressive behavior.

Fibrosarcoma is another rare mesenchymal tumor. Due to the extremely low number of cases no standard therapy has been established for these patients. Limited evidence suggests that low-grade fibrosarcomas have relatively good prognosis [20].

It is worth mentioning that in both cases histopathological diagnosis was delayed due to additional staining and the need for consultations between pathologists. This limited the possibility of adjuvant therapy.

Indications and contraindications for endoscopic surgery of paranasal malignancies have been evolving over the past decade. Involvement of the dura, pterygopalatine and infratemporal fossa are no longer treated as contraindications to endoscopic surgery. The radical removal of tumors involving the skull base is nowadays technically possible but requires experienced, highly skilled teams of ENT and neurosurgeons.

\section{Conclusions}

Although our study group is relatively small and the observation period is short, our initial experience seems to confirm results obtained by other authors, thus indicating that in selected cases endo- scopic surgery of sinonasal malignancies is effective in a similar degree to external approach surgery.

\section{References}

1. Thompson LDR. Sinonasal carcinomas. Curr Diagn Pathol 2006; 12: 40-53.

2. Grau C, Jakobsen MH, Harbo G, et al. Sino-nasal cancer in Denmark 1982-1991 - a nation widesurvey. Acta Oncol 2010; 40: 12-23.

3. Lund V, Stamberger H, Nicolai P, et al. European position paper on endoscopic management of tumors of the nose and paranasal sinuses and skull base. Rhinology 2010; Suppl. 22: 1-143.

4. Carillo JF, Guemes A, Ramirez-Ortega MC, Onate-Ocana LF. Prognostic factors in maxillary sinus and nasal cavity carcinoma. EJSO 2005; 31: 1206-12.

5. Żytka S, Bień S, Kamiński B, et al. Epidemiology and clinical characteristics of the sinonasal malignancies. Otolaryngol Pol 2008; 62: 436-41.

6. Ketcham AS, Wilkins RH, Vanburen JM, Smith RR. A combined intracranial facial approach to the paranasal sinuses. Am J Surg 1963; 106: 698-703.

7. Lombardi D, Tomenzoli D, Butta L, et al. Limitations and complications of endoscopic surgery for treatment for sinonasal inverted papilloma: a re-assessment after 212 cases. Head Neck 2011; 33: 1154-61.

8. Busquets JM, Hwang PH. Endoscopic resection of sinonasal inverted papilloma: a meta-analysis. Otolaryngol Head Neck Surg 2006; 134: 476-82.

9. Gotlib T, Krzeski A, Held-Ziółkowska M, Niemczyk K. Endoscopic transnasal management of inverted papilloma involving frontal sinuses. Videosurgery Miniinv 2013; 7: 299-303.

10. Boghani Z, Husain Q, Kanumuri VV, et al. Juvenile nasopharyngeal angiofibroma: a systematic review and comparison of endoscopic, endoscopic-assisted, and open resection in 1047 cases. Laryngoscope 2013; 123: 859-69.

11. Nicolai P, Battaglia P, Bignami M, et al. Endoscopic surgery for malignant tumors of the sinonasal tract and adjacent skullbase: a 10-year experience. Am J Rhinol 2008; 22: 308-16.

12. Hanna E, DeMonte F, Ibrhim S, et Al. Endoscopic resection of sinonasal cancers with and without craniotomy. Arch Otolaryngol Head Neck Surg 2009; 135: 1219-24.

13. Suh JD, Ramakrishnan VR, Chi JJ, et al. Outcomes and complications of endoscopic approaches for malignancies of paranasal sinuses and anterior skull base. Ann Otol Rhinol Laryngol 2013; 122: 54-9.

14. Nicolai P, Castelnuovo P, Villaret AB. Endoscopic resection of sinonasal malignancies. Curr Oncol Rep 2011; 13: 138-44.

15. Hadad G, Bassagasteguy L, Carrau RL, et al. A novel reconstructive technique after endoscopic expanded endonasal approaches: vascular pedicled nasoseptal flap. Laryngoscope 2006; 116: 1882-6.

16. Gomez-Rivera F, Fakhri S, Williams MW, et al. Surgical management of sinonasal hemangiopericytomas: a case series. Head Neck 2012; 34: 1492-6.

17. Bignami M, Dallan I, Battaglia P, et al. Endoscopic, endonasal management of sinonasal hemangiopericytoma: 12-year experience. J Laryngol Otol 2010; 124: 1178-82. 
18. Billings KR, Fu SY, Calcaterra TC, Sercarz JA. Hemangiopericytoma of head and neck. Am J Otolaryngol 2000; 21: 238-43.

19. Thmpson LDR, Miettinen M, Wenig BM. Sinonasal-type hemangiopericytoma. A clinicopathological and immunophenotypic analysis of 104 cases showing perivascular and myoid differentiation. Am J Surg Pathol 2003; 27: 737-49.

20. Bahrami A, Folpe AL. Adult-type fibrosarcoma: a reevaluation of 163 putative cases diagnosed at a single institution over a 48year period. Am J Surg Pathol 2010; 34: 1504-13.

Received: 19.06.2013, accepted: 9.09.2013. 